\title{
Behaviour of corrugated steel plate bridge with high soil cover under seismic excitation
}

\author{
Tomasz Maleska, and Damian Beben* \\ Opole University of Technology, Faculty of Civil Engineering and Architecture, 45-061 Opole, \\ Katowicka 48, Poland
}

\begin{abstract}
The design codes and calculation methods related to the corrugated steel plate (CSP) bridges and culverts say only on the minimum soil height. This value is connected with the bridge span and shell height. In the case of static and dynamic loads (like passing the vehicles), such approach seems to be reasonable. However, it is important to know how the CSP bridges with high the soil covers behave under the seismic loads. This paper is presented the result of numerical study of CSP bridge with different high cover under seismic excitation. The analysed CSP railway bridge in the cross section has two closed pipe-arches. The span of shells is $4.40 \mathrm{~m}$ and the height of shells is $2.80 \mathrm{~m}$. The load-carrying structure was constructed as two shells assembled from CSP sheets, designed with a depth of $0.05 \mathrm{~m}$, pitch of $0.15 \mathrm{~m}$, and plate thickness of $0.003 \mathrm{~m}$. The real soil cover depth over the CSP structure (including ballast, blanket and backfill) equals 2.40 $\mathrm{m}$. In this study two heights of soil cover were analysed $(2.40 \mathrm{~m}$ and 5.00 $\mathrm{m})$. Numerical analysis was conducted using the DIANA program based on finite element method (FEM). A linear model with El Centro records and Time History was used to analyse the problem.
\end{abstract}

\section{Introduction}

In recent years corrugated steel plate (CSP) bridges have become increasingly popular (Fig. 1) often displacing traditional bridge solutions like reinforced concrete, steel or wooden bridges. Undoubtedly, the advantages of these structures have contributed to the increase of their popularity. Above all, low construction costs and fast time of erection should be mentioned here. It is also worth adding that the structures are part of the idea of sustainable development.

\footnotetext{
${ }^{*}$ Corresponding author: d.beben@po.opole.pl
} 


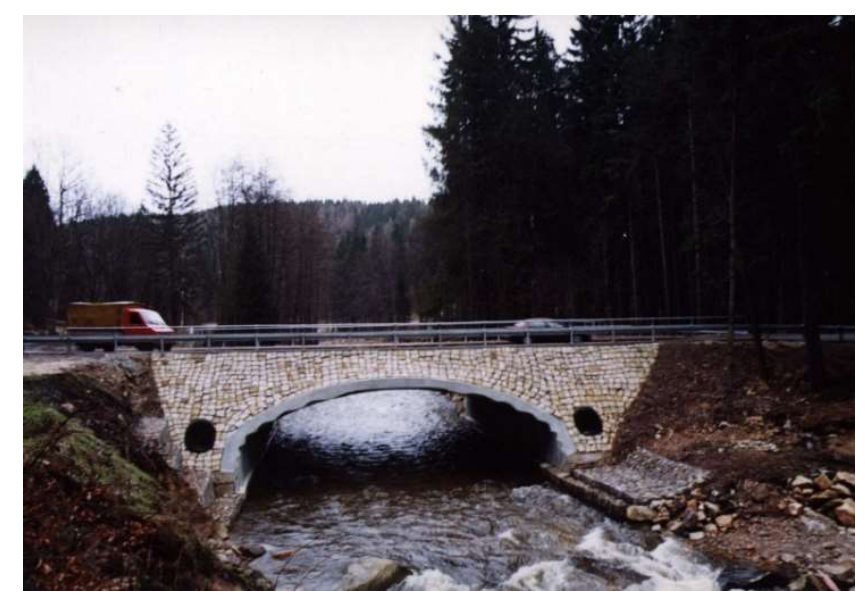

Fig. 1. Example of corrugated steel plate bridge.

CSP structures usually occur up to span of $25 \mathrm{~m}$. It affects the limited scope of their application which is small and medium span bridges [1]. CSP bridges, in comparison with traditional ones, have one fundamental difference. Load-carrying capacity in case of traditional bridges usually diminish with the course of time. While CSP bridges load capacity increases as a result of backfill density increase [2, 3]. Moreover the phenomena of arching in the soil occurs which has an impact on reduce loads acting on steel shell structure and extending the whole life time of object [4].

Increasing popularity of CSP bridges made a lot of researchers interested in this type of structures which can be proven by appearance of numerous publications. Various types of impacts on a CSP structure have been analysed. Beben and Stryczek [2] analysed the impact of standard load on a CSP bridge with reinforced concrete (RC) relieving slab built-in over a shell structure. Lower stresses and displacements were obtained as a result of the use of $\mathrm{RC}$ relieving slab. The numerical programme Abaqus based on the finite element method was used for computational analysis. The works $[6,7]$ also carried out the analyses for the dynamic load of CSP bridges. The works analysed the impact of dynamic loads on shells with closed [6] and box [7] cross-section.

The authors also conducted the analyses of bridges interacting with the soil regarding seismic impacts. However, in most cases the works concern the impacts on RC culverts (box and arch ones). The example can be the paper [8] where the impact of seismic excitations on a RC culvert structure of arch cross-section was analysed be means of Time History method. The analysis of seismic excitations on a CSP bridge shell was conducted in the paper [9]. The impact of seismic excitations on a bridge as a result of different directions of activation (perpendicular and parallel to a bridge structure) was analysed. Davis and Bardet [10] studied the impact of seismic excitations on steel culverts structures buried in the ground. The effects that occurred in a steel shell after an earthquake were evaluated. Abuhajtar et al. [11] analysed the impact of seismic excitations on box cross-section structures. For proper evaluation of tremors impact on these structures three different kinds of excitation records were used. The same was done in the paper [12] where, to analyse the impact of tremors on a steel shell structure, various earthquake records were used. In this case the results of numerical analysis were confronted with a standard [13]. It 
was found that consistency of obtained results with the standard records occurs only in case of a shorter tremor with high ground acceleration.

The aim of this article is to present the impact of seismic excitations on a CSP bridge of different soil cover depth over the shell. It is known that soil cover depth influences the obtained values of internal forces while analysing these bridges under static and dynamic loads. Additionally, the paper analysed accelerations and speeds of shell structure vibrations. A selected real bridge model was subjected to excitation caused by El Centro earthquake from 1940. The record is considered to be a model for analysing a structure under a seismic load.

\section{Description of the analysed numerical model}

\subsection{Description of a CSP bridge}

To conduct the analysis of seismic excitations impact on a CSP bridge a real object located in Poland was used. It is built of two shells, each of them has a span of $L 1=L 2=4.40 \mathrm{~m}$ (Fig. 2). A cross-section is of a pipe-arch shape. The load-carrying structure was constructed as two shells assembled from CSP sheets, designed with a depth of $0.05 \mathrm{~m}$, pitch of $0.15 \mathrm{~m}$, and plate thickness of $0.003 \mathrm{~m}$. The height of shells is $2.80 \mathrm{~m}$. Backfill surrounding steel shell structures was laid in layers of $0.20 \mathrm{~m}$ and properly compacted to reach the density index of $0.98-0.95$ on the Proctor scale. Soil cover depth over the shell crown equals $2.40 \mathrm{~m}$. The CSP bridge is $21.80 \mathrm{~m}$ long at the bottom and $16.00 \mathrm{~m}$ long at the top (in a shell crown).

\subsection{Description of a numerical model}

A numerical programme DIANA FEA [14] basing on the finite elements method was used in the paper. In order to map the behaviour of the analysed bridge under a seismic load in a numerical model, the following material characteristics were adopted:

- steel plate corrugated was modelled as shell curved elements (Q24IF), Young modulus of $205 \mathrm{GPa}$, Poisson ratio of 0.3 , elastic-plastic model with density of 7850 $\mathrm{kg} / \mathrm{m}^{2}$, the yield strength of steel of $235 \mathrm{MPa}$, moment of inertia of $1176.6 \mathrm{~mm}^{4} / \mathrm{mm}$, cross section area of $3.77 \mathrm{~mm}^{2} / \mathrm{mm}$, and plate thickness of $0.003 \mathrm{~m}$,

- backfill with height of $2.4 \mathrm{~m}$ and $5.0 \mathrm{~m}$ was modelled as solid elements (HX24L) with the Duncan-Chang nonlinear elastic hyperbolic model with Young's modulus of $100 \mathrm{MPa}$, material density of $2050 \mathrm{~kg} / \mathrm{m}^{2}$, Poisson ratio of 0.2 , dilation angle of $5^{\circ}$, angle of internal friction of $39^{\circ}$, cohesion of $3000 \mathrm{~N}$, failure ratio $R_{f}=0.7$, unloading-reloading stiffness $E_{u \mathrm{r}}=1000 \mathrm{~N} / \mathrm{m}^{2}$, reference pressure $P_{\text {ref }}=101350$ $\mathrm{N} / \mathrm{m}^{2}$, exponent for unloading reloading curve $m=0.25$, exponent for backbone curve $n=1.1$, minimum compressive stress of $350 \mathrm{~N} / \mathrm{m}^{2}$, and minimum tangential stiffness of backbone curve $E_{t, \min }=1200 \mathrm{~N} / \mathrm{m}^{3}$, 


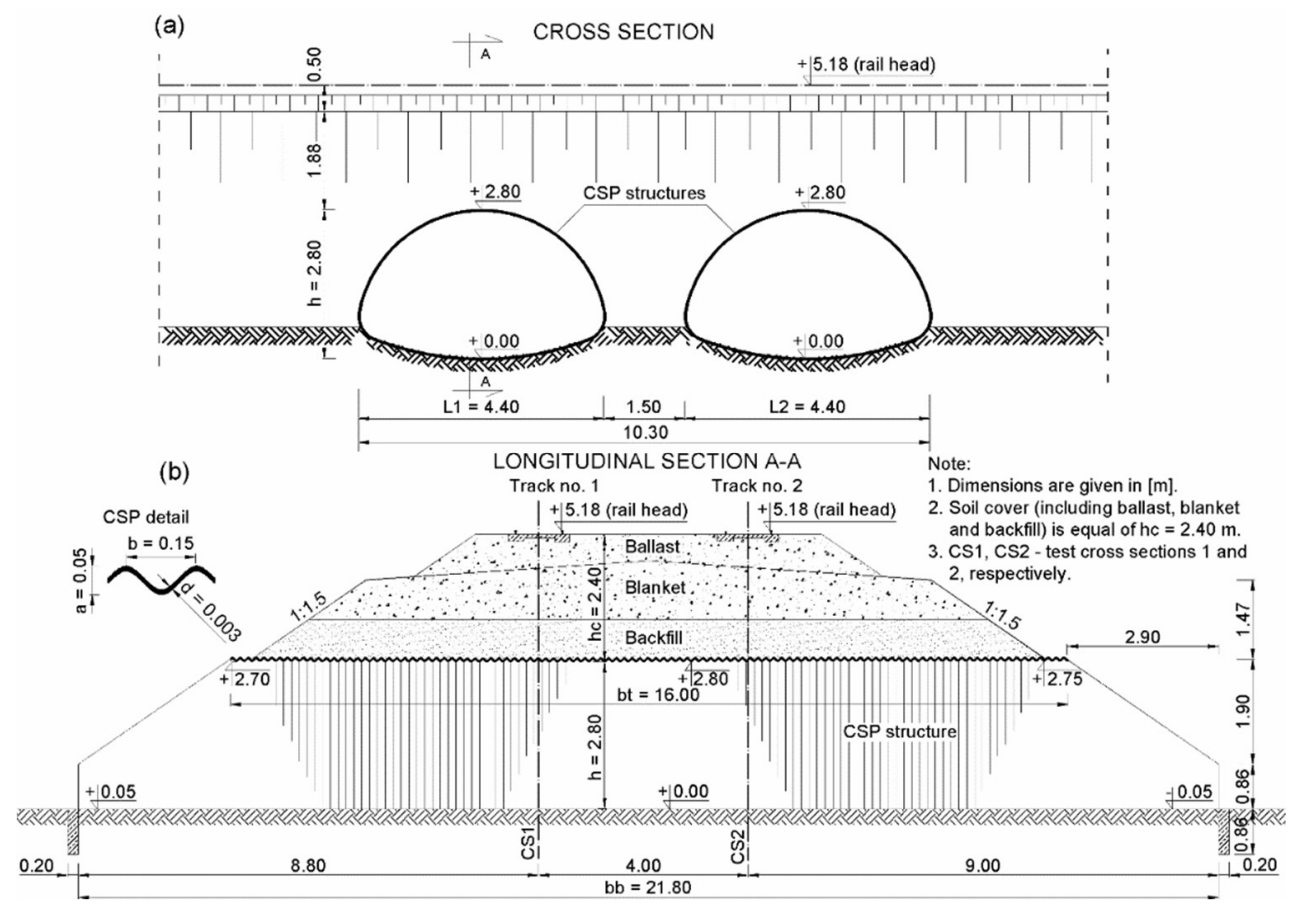

Fig. 2. Analysed bridge: a) cross-section, b) longitudinal section.

- boundary condition were modelled as non-transferable support of the shell walls and on all boundary walls of the soil for $\mathrm{x}, \mathrm{y}, \mathrm{z}$ directions,

- connection between soil and steel was modelled as automatic interface by applied function "Coulomb friction" with angle of internal friction of $39^{\circ}$, dilation angle of $5^{\circ}$, rigidity of $100000 \mathrm{kN} / \mathrm{m}^{3}$, and cohesion of $3000 \mathrm{~N}$,

- the finite element was modelled as quadratic elements with dimensions of $0.25 \times 0.25 \mathrm{~m}$ for backfill and steel shell corrugated (Fig. 3).

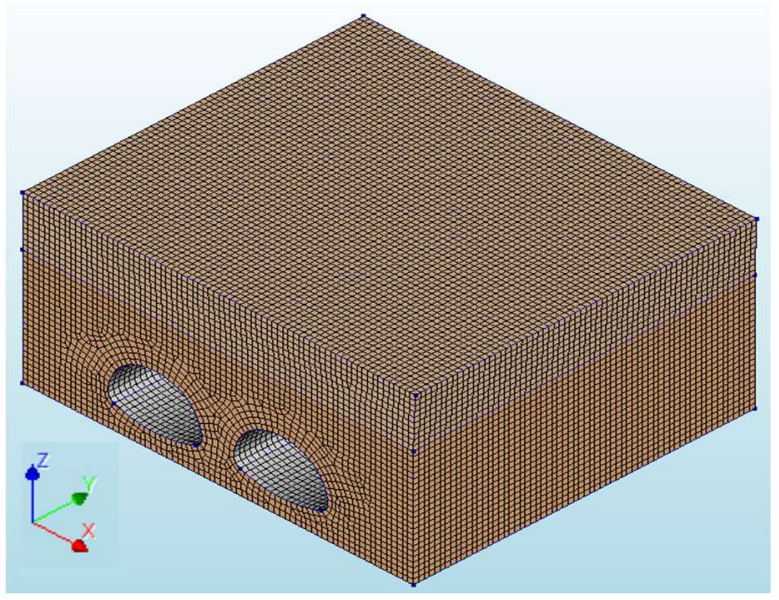

Fig. 3. Numerical model of CSP bridge with soil cover of $5.0 \mathrm{~m}$. 
A corrugated shell was modelled as a flat one using orthotropic characteristics. Because of such approach the calculation time was shortened [5]. The applied simplification was made in accordance with procedures included in works $[5,9,15]$. An orthotropic shell was defined using the following correlations (1-4):

- equivalent thickness of plate:

$$
t_{\text {equ }}=\sqrt{12\left(1-v^{2}\right) \frac{I}{A}}
$$

where $I$ is moment of inertia, $A$ is cross-sectional area, $v$ is Poisson ratio $\left(v=v_{x}=\right.$ $0.3)$,

- equivalent elastic modulus of material (Young modulus) in circumferential direction of shell:

$$
E_{x, e q u}=E \frac{A}{a t_{\text {equ. }}},
$$

where $a$ is a pitch of corrugation, $E$ is Young modulus,

- equivalent elastic shear modulus:

where $t$ is a plate thickness,

$$
E_{y, \text { equ }}=E\left(\frac{t}{t_{\text {equ. }}}\right)^{3},
$$

- equivalent Poisson ratio:

$$
v_{\text {equ }}=v \frac{E_{y, e q u .} .}{E_{x, \text { equ. }} .}
$$

\section{Results of a CSP bridge seismic analysis}

The linear analysis using Time History method was applied in the work. A standard record of El Centro seismic excitation [16] was implemented. The record is characterised by a magnitude of 6.9 on Richter scale and a ground acceleration of $3.44 \mathrm{~m} / \mathrm{s}^{2}$. El Centro earthquake is considered as an extreme one and the effects of the phenomena are described as catastrophic. A seismic load was applied to the bridge in two directions, that is „X" - perpendicular and „Y" - parallel. Moreover, the case of two different soil cover depth over the steel shell crown which are $2.4 \mathrm{~m}$ and $5.0 \mathrm{~m}$ were analysed. Maximum analysis results are presented in Table 1.

Table 1. Maximal values in steel shell and backfill from El Centro earthquake.

\begin{tabular}{|c|c|c|c|c|}
\hline \multirow{2}{*}{ Value } & \multicolumn{4}{|c|}{ Soil cover depth over the crown shell (m): } \\
\cline { 2 - 5 } & \multicolumn{3}{|c|}{$\mathbf{2 . 4}$} & \multicolumn{2}{c|}{$\mathbf{5 . 0}$} \\
\cline { 2 - 5 } & \multicolumn{3}{|c|}{ Direction of seismic load application: } \\
\cline { 2 - 5 } & ,X" & ,Y" & "X" & "Y" \\
\hline $\begin{array}{c}\text { Shell displacements } \\
(\mathrm{m})\end{array}$ & 0.059 & 0.059 & 0.078 & 0.078 \\
\hline $\begin{array}{c}\text { Backfill displacements } \\
(\mathrm{m})\end{array}$ & 0.062 & 0.062 & 0.099 & 0.099 \\
\hline $\begin{array}{c}\text { Stresses in steel shell } \\
(\mathrm{MPa})\end{array}$ & -166 & -166 & -217 & -217 \\
\hline
\end{tabular}




\begin{tabular}{|c|c|c|c|c|}
\hline $\begin{array}{c}\text { Stresses in backfill } \\
(\mathrm{MPa})\end{array}$ & -2.871 & -2.870 & -3.689 & -3.686 \\
\hline $\begin{array}{c}\text { Axial thrusts } \\
(\mathrm{kN} / \mathrm{m})\end{array}$ & -1306.78 & -1306.78 & -1763.04 & -1763.04 \\
\hline $\begin{array}{c}\text { Bending moments } \\
(\mathrm{kNm} / \mathrm{m})\end{array}$ & 97.62 & 97.62 & 124.41 & 124.41 \\
\hline $\begin{array}{c}\text { Accelerations } \\
\left(\mathrm{m} / \mathrm{s}^{2}\right)\end{array}$ & 30.40 & 35.31 & 17.33 & 25.20 \\
\hline $\begin{array}{c}\text { Vibration speed } \\
(\mathrm{m} / \mathrm{s})\end{array}$ & 0.22 & 0.42 & 0.27 & 0.18 \\
\hline
\end{tabular}

\subsection{Values of internal forces, displacements and stresses}

As a result of Time History analysis the biggest displacements of a steel shell were obtained for $5.0 \mathrm{~m}$ soil cover depth which amounted to $0.078 \mathrm{~m}$ (Fig. 4a). Whereas for $2.4 \mathrm{~m}$ height of soil cover, the shell displacement was lower by $24.4 \%$ and reached the value of $0.059 \mathrm{~m}$. For two investigated directions of , $\mathrm{X}$ ” and „Y" seismic load, the same maximum steel shell displacements were obtained and observed at a structure crown.

a)

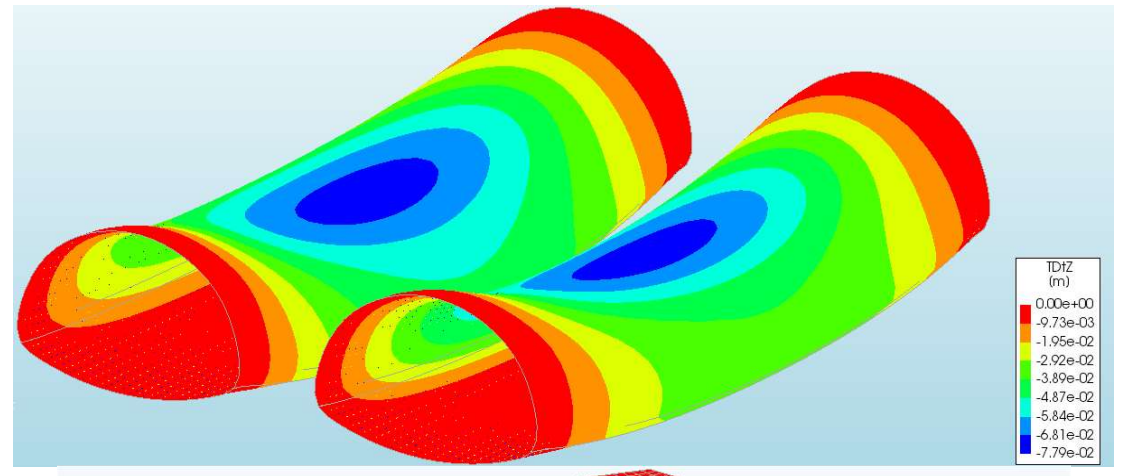

b)

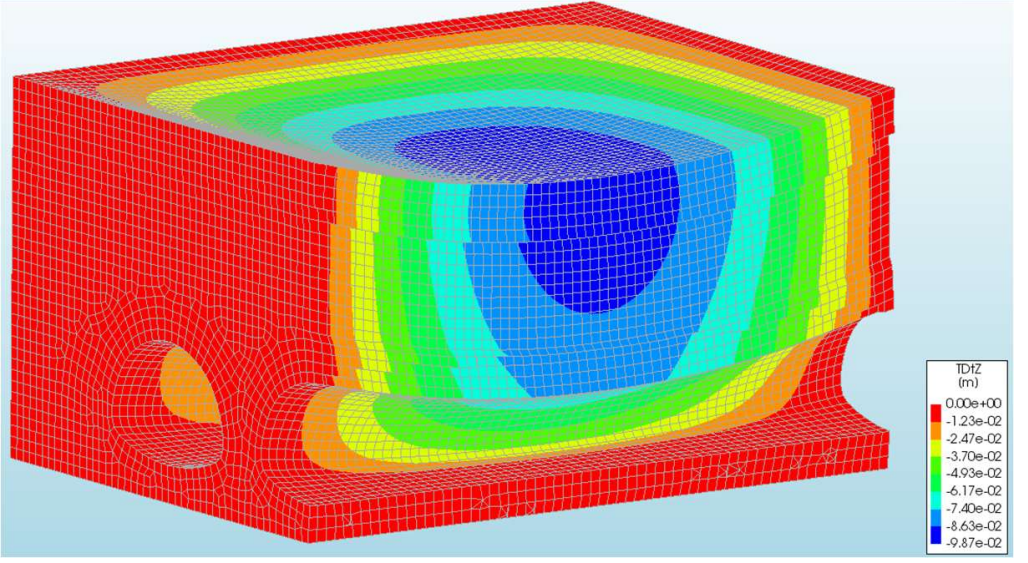

Fig. 4. Maximum displacements (X direction) in: a) steel shell and b) backfill.

An important aspect is also the backfill deformation around the shell caused by seismic excitation. It is worth to mention that a maximum backfill displacement was obtained for a bridge with soil cover depth of $5.0 \mathrm{~m}$ and amounted $0.099 \mathrm{~m}$ (Fig. 4b). 
For the soil cover height of $2.4 \mathrm{~m}$ a maximum displacement was lower by $37.4 \%$ and amounted $0.062 \mathrm{~m}$. A maximum backfill displacement was observed over the shell structure crown in a middle part of the analysed model. They were larger than steel shell displacements. It is connected with loads redistribution by soil layers and reduction of a direct impact on a bridge shell.

The largest stresses in a steel shell were also obtained for a model with soil cover depth of $5.0 \mathrm{~m}$ (Fig. 5a). In this case the value of maximum stresses, both for direction "X" and "Y", was -217 MPa. For the bridge with soil cover of $2.4 \mathrm{~m}$, the stresses were lower by $23.5 \%$ and amounted $-166 \mathrm{MPa}$. Maximum values were noticed near the shell support (in the vicinity of the second shell) and their character was compressive.

Maximum stresses in a backfill, just like in a steel shell, were also observed for a model with soil cover depth of $5.0 \mathrm{~m}$ (Fig. 4b) and on the "X" direction of seismic excitation.

Their value

was

$-3.689 \mathrm{MPa}$ and they were compressive ones. The largest stresses occurred near the steel shell support (in the point where two shells meet). For the CSP bridge model with a soil cover height of $2.4 \mathrm{~m}$, the maximum stresses in a backfill were lower by $22.2 \%$ than the ones obtained for the cover of $5.0 \mathrm{~m}$. The direction of seismic excitation action has little influence on stresses in a backfill. For soil cover of $2.4 \mathrm{~m}$ and $5.0 \mathrm{~m}$ the differences between stresses in direction " $\mathrm{X}$ " and " $\mathrm{Y}$ " were $0.03 \%$ and $0.08 \%$ respectively.

The largest area of maximum axial thrusts occurrence was observed in the point were two shells meet. The area reached from the level of a steel shell foundation to about $1 / 3$ of its height (Fig. 6a). The place of axial thrusts occurrence was the same for soil cover depths of $2.4 \mathrm{~m}$ and $5.0 \mathrm{~m}$ (Table 1) and they were of a compressive character. However, for a soil cover of $5.0 \mathrm{~m}$ they were significantly higher than for the cover of $2.4 \mathrm{~m}$, they were higher by $34.9 \%$ and amounted $-1763.04 \mathrm{kN} / \mathrm{m}$.

a)

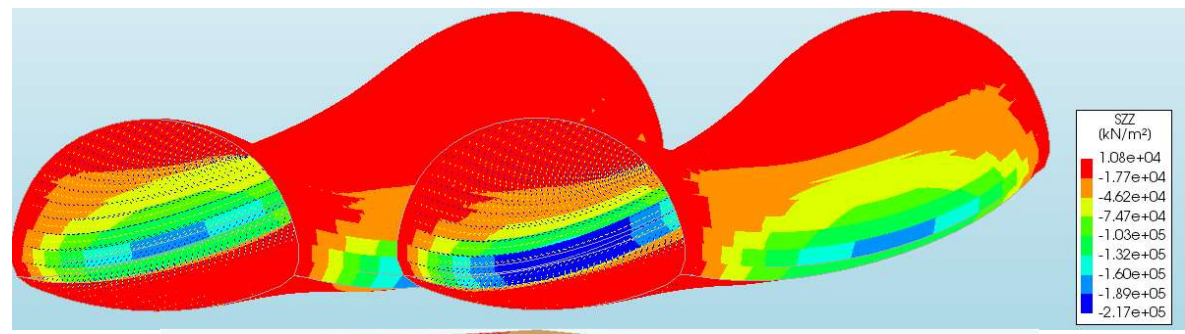

b)

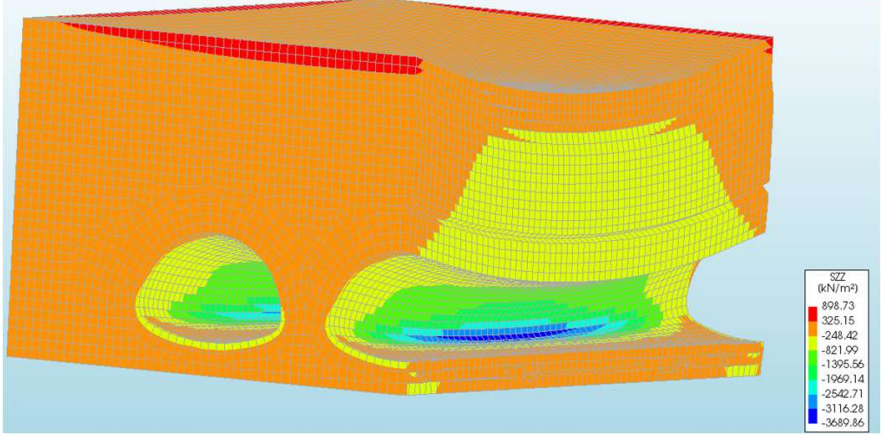

Fig. 5. Maximum stresses (X direction) in: a) steel shell, b) backfill. 
The maximum values of bending moments were obtained in the area of the vicinity of two shells and they were of tension character. In this case the maximum bending moment amounted $124.41 \mathrm{kNm} / \mathrm{m}$ (Fig. 6b). As in previous cases, the values were the same for two directions (,X” and "Y") of a seismic excitation. Maximum values were obtained for a model with soil cover depth of $5.0 \mathrm{~m}$. However, for the model with cover of $2.4 \mathrm{~m}$, a maximum bending moment value lower by $21.5 \%$ was obtained.

a)

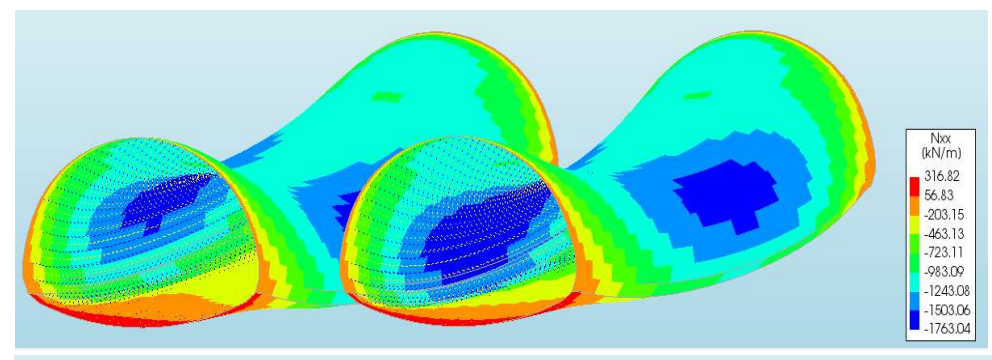

b)

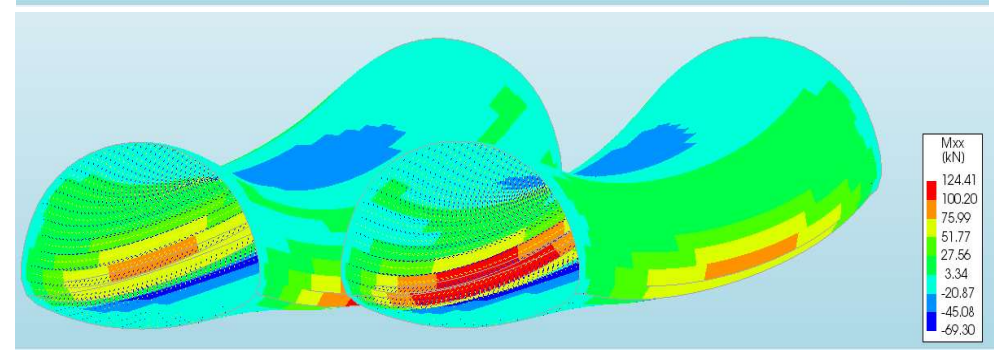

Fig. 6. Maximum values (X direction) of: a) axial thrusts, b) bending moments.

\subsection{Accelerations and velocities of vibrations}

Additionally, the analysis of velocities and accelerations of vibrations caused by El Centro earthquake was conducted in the paper. After the analysis of obtained results from numerical calculations it was stated that the direction of a seismic load application and the soil cover over the shell has an impact on obtained values of vibrations and accelerations of the analysed structure.

The highest vibration acceleration of shell structure amounted $35.31 \mathrm{~m} / \mathrm{s}^{2}$ (Fig. 7a) and it was observed in case of a bridge with soil cover of $2.4 \mathrm{~m}$. Maximum acceleration was achieved when the frequency of vibrations equalled $11.744 \mathrm{~Hz}$. The value was obtained during seismic excitation application on the "Y" direction (parallel to the bridge). In the case of "X" direction (perpendicular to the structure), the maximum acceleration was lower by $13.9 \%$ than the ones obtained on the direction "Y" and amounted $30.40 \mathrm{~m} / \mathrm{s}^{2}$. In this case the frequency of vibrations equalled $10.241 \mathrm{~Hz}$. For bridge with the soil cover depth of $5.0 \mathrm{~m}$, the maximum vibration acceleration was $25.20 \mathrm{~m} / \mathrm{s}^{2}$ and it was observed on the "Y" direction at the $10.155 \mathrm{~Hz}$ frequency of vibrations. For this model the acceleration was higher by $28.6 \%$ than the ones obtained for soil cover of $2.4 \mathrm{~m}$. Thus the acceleration of a bridge with the cover of $5.0 \mathrm{~m}$ on the " $\mathrm{X}$ " direction was lower by $50.9 \%$ (Table 1 ) than the value achieved for soil cover of $2.4 \mathrm{~m}$. The frequency of structure vibrations in this case amounted $8.588 \mathrm{~Hz}$. 
a)

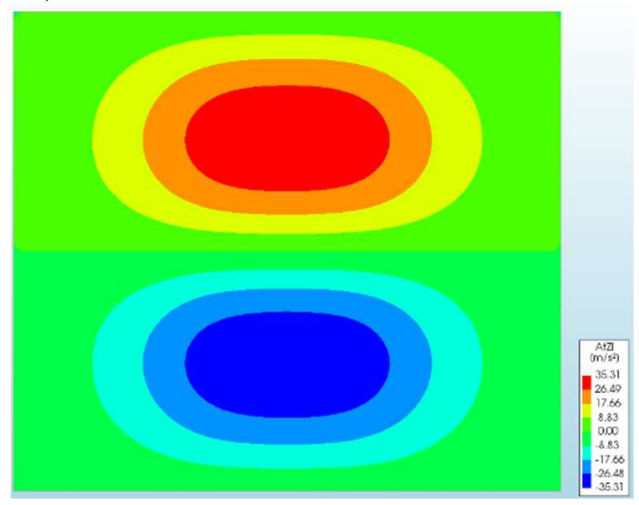

b)

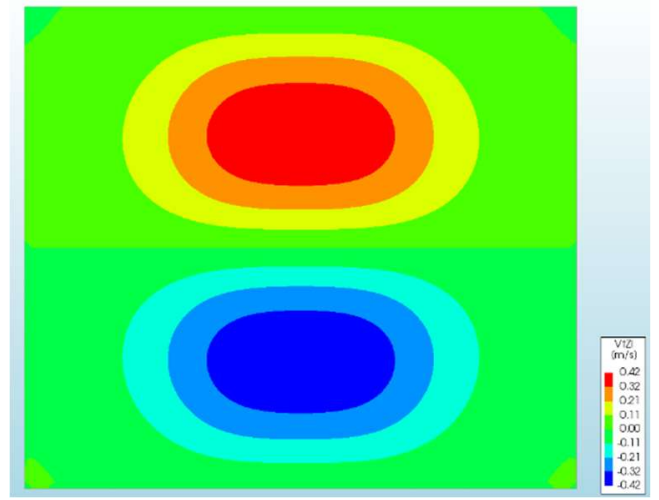

Fig. 7. Maximum values from the El Centro excitation (top view): a) accelerations, b) vibration velocities.

Similar tendencies were observed in case of vibration velocity of shell structure where the maximum values were also obtained for the soil cover height of $2.4 \mathrm{~m}$ and "Y" direction of the seismic excitation. In this case, the maximum value of vibrations amounted $0.42 \mathrm{~m} / \mathrm{s}$ (Fig. 7b) at the $11.434 \mathrm{~Hz}$ frequency of vibrations. On the perpendicular direction „X”, the vibration velocity was observed lower by $47.6 \%$ which is $0.22 \mathrm{~m} / \mathrm{s}$ at the frequency of vibrations equal $10.241 \mathrm{~Hz}$. In the case of a bridge model with the soil cover of $5.0 \mathrm{~m}$, the maximum vibrations velocity was lower by $35.7 \%$ and $57.1 \%$ on the "X" and "Y" directions, respectively, than the ones obtained for a bridge model with the soil cover of $2.4 \mathrm{~m}$. In this case the frequency of bridge shell vibrations equalled $8.864 \mathrm{~Hz}$ and $9.047 \mathrm{~Hz}$, respectively for "X" and "Y" directions.

\section{Conclusions}

As a result of conducted numerical analysis of a CSP bridge under the seismic excitation with the use of DIANA FEA programme, the following conclusions can be drawn:

- Increased soil cover depth causes larger values of internal forces and displacements caused by an earthquake (El Centro excitation). It was observed that the direction of seismic excitation application does not influence the values of internal forces and displacements.

- Maximum bending moments and axial thrusts were achieved in a bridge model with the soil cover of $5.0 \mathrm{~m}$ and they were $124.41 \mathrm{kNm} / \mathrm{m}$ and $-1763.04 \mathrm{kN} / \mathrm{m}$, respectively. For a model with the soil cover height of $2.4 \mathrm{~m}$, the bending moments and axial thrusts were lower by $21.5 \%$ and $34.9 \%$, respectively. In case of stresses, the difference between maximum values in a steel shell for both considered soil cover heights was $23.5 \%$. The maximum values were obtained for a bridge with the soil cover of $5.0 \mathrm{~m}$. Maximum bending moments and stresses in a shell occurred in the same places - in a vicinity of a shell support (haunches). Whereas maximum axial thrusts also occurred near a steel shell foundation, 
whereby the area was stretching towards a shell crown. On the outside of shells sides, much lower values of internal forces were obtained. It proves that a small distance between shells $(1.50 \mathrm{~m})$ influences the cumulation of stresses, bending moments and axial thrusts (the load redistribution effect is limited here).

- The largest vertical displacements were observed in a backfill and they amounted $0.099 \mathrm{~m}$. They were higher by $26.9 \%$ than steel shell displacements. Maximum backfill and shell displacements were obtained for a model with the soil cover depth of $5.0 \mathrm{~m}$.

- The increase of a soil cover depth over a shell causes lower accelerations, velocities and frequencies of structure vibrations caused by El Centro seismic excitation. The highest accelerations and velocity of vibrations were observed in case of the soil cover of $2.4 \mathrm{~m}$ and "Y" direction of excitation. Maximum acceleration was $35.31 \mathrm{~m} / \mathrm{s}^{2}$, and the velocity of vibrations equalled $0.42 \mathrm{~m} / \mathrm{s}$. In case of a bridge with the soil cover of $5.0 \mathrm{~m}$, acceleration and velocity of vibration was lower by $28.6 \%$ and $35.7 \%$, respectively. Undoubtedly it proves a beneficial impact of a backfill height on safety of a CSP bridge subjected to influence of an earthquake.

- The direction of seismic excitation is also important in case of accelerations and velocities of the structure vibration. It was observed that the highest acceleration and velocity of vibrations occurred on the (parallel) excitation direction "Y" (in a model with the soil cover depth of $2.4 \mathrm{~m}$ ). Maximum accelerations and velocities of bridge shell vibrations on the " $\mathrm{X}$ " direction were lower by $13.9 \%$ and $47.6 \%$, respectively, than the one obtained from a seismic excitation acting on "Y" direction.

- It was found that a steel yield strength (235 MPa) will not be exceeded. Obtained maximum stresses of $-217 \mathrm{MPa}$ constitute $92.3 \%$ of an assumed yield strength. Therefore the bridge will not get destroyed and will survive a strong earthquake. However, there is a risk that due to, for example, weather conditions and with the course of time, there will be a change in a structure behaviour characteristics and assumptions undertaken during design and analysis. In order to formulate more general conclusions regarding the work of CSP bridges under seismic load further work is necessary.

\section{References}

1. L. Janusz, A. Madaj, Engineering Structures from Corrugated Plate: Design and Construction, Transport and Communication Publishers, Warsaw, Poland (2009)

2. D. Beben, Corrugated steel plate (CSP) culvert response to service train loads. Journal of Performance of Constructed Facilities, 28 (2014)

3. H. Sezen, K. Y. Yeau, P. J. Fox, In-situ load testing of corrugated steel pipe-arch culverts, Journal of Performance of Constructed Facilities, 22 (2008)

4. Cz. Machelski, Modeling of Soil-Shell Bridges Structures, The Lower Silesian Educational Publishers, Wroclaw, Poland (2008)

5. D. Beben, A. Stryczek, Numerical analysis of corrugated steel plate bridge with reinforced concrete relieving slab, Journal of Civil Engineering and Management, 22 (2016) 
6. D. Beben, Application of the interferometric radar for dynamic tests of corrugated steel plate (CSP) culvert, NDT\&E International, 44 (2011)

7. D. Beben, Dynamic amplification factor of corrugated steel plate culverts, Engineering Structures, 46 (2013)

8. Y. Sawamura, K. Kishida, M. Kimura, Experimental study on seismic resistance of a two-hinge precast arch culvert using strong earthquake response simulator, The $15^{\text {th }}$ Asian Regional Conference on Soil Mechanics and Geotechnical Engineering (2015)

9. T. Maleska, P. Bońkowski, D. Beben, Z. Zembaty, Transverse and longitudinal seismic effects on soil-steel bridges, Conference: Eight European Workshop on the Seismic Behaviour of Irregular and Complex Structures (2017)

10. C. A. Davis, J. P. Bardet, Responses of buried corrugated metal pipes to earthquakes, Journal of Geotechnical and Geoenvironmental Engineering, 126 (2000)

11. O. Abuhajtar, H. El Naggar, T. Newson, Seismic soil-culvert interaction, Canadian Geotechnical Journal, 52 (2015)

12. A. Maghgoub, H. El Naggar, Assessment of seismic provisions of the CHBDC for CSP culverts, Conference: GeoOttawa 2017 (2017),

13. CHBDC, Canadian Highway Bridge Designe Code. CAN/CSA-S6-06, Canadian Standards Association International (2006)

14. DIANA FEA, Available online from URL: www.dianadea.com/ (2017)

15. G. Pittino, J. Gosler, Structural plate steel underpasses during backfilling - how to minimize the bending moment, Conference: 4th International FLAC Symposium on Numerical Modelling in Geomechanics (2006)

16. L. Yongle, S. Zhu, C. S. Cai, C. Yang, S. Qiang, Dynamic Response of Railway Vehicles Running on Long-Span Cable-Stayed Bridge Under Uniform Seismic Excitations, International Journal of Structural Stability and Dynamics, 16 (2016) 